\title{
KAWABATA: PEQUENAS TRADUÇõeS (1)
}

\author{
Madalena Natsuko Hashimoto
}

\begin{abstract}
Yasunari Kawabata (1899-1972), escritor internacionalmente conhecido no Ocidente, após ter sido laureado pelo prêmio Nobel, em 1968, tem sido considerado por todos que o lêem como "o mais japonês dos escritores". Mas isto é pouco: o Japão é vários mundos. seus romances mais difundidos (Yuki Guni, Senbazuru, Yama no Oto) encontram-se já traduzidos em várias línguas. Mas um pequeno livro que marcou a revelação de seu mundo poético através de uma forma que nada fica a dever aos romances de maior fôlego é ainda muito pouco difundido: Tanagokoro no Shôsetsu, literalmente "contos da palma-da-mão". Trata-se de uma coleta de textos muito curtos e extremamente poéticos; são como que vinhetas, pequenos flashes de situações e/ou meditações. Analisemos a tradução de algumas destas estórias.
\end{abstract}

\section{RECIPIENTES FRĀGEIS (Yowaki Utsuwa)}

Num cruzamento da cidade, havia um antiquário. Entre a loja e a rua se postava a estátua de porcelana da deusa Kanzeon, protetora das mulheres. Tinha a estatutra de uma menina de doze anos. Quando o trem passava, tremiam juntos, levemente, o trem, a porta de vidro da rua, a loja, a pele fria de Kanzeon. Toda vez que eu passava em frente, temia a possibilidade desta estátua cair na rua. Por causa disto, sonhei. mim.

O corpo de Kanzeon veio tombando, virando-se diretamente para

Estendendo repentinamente os braços brancos que caíam roliços e longos, agarrou firmemente o meu pescoço. Pulei para trás, estranhando o tato frio da porcelana e o fato do braco inanimado tomar vida.

Kanzeon, sem emitir som, despedaçou-se na rua.

E ela catava aqueles cacos.

Ela se agachou um pouco, catou, apressadamente, os cacos de porcelana.

Assustei-me com a sua súbita aparição e quando tentei esboçar algo com a intenção de me desculpar, acordei. 
Tentei interpretar este sonho. tes frágeis!

- Vocês também, tratem suas esposas como se fossem recipien-

Estas palavras da Bíblia sempre vinham à minha mente nesta época. As palavras eram: recipientes frágeis. Associava-as sempre aos recipientes de porcelana de Seto. E, além disso, associava-as a ela.

As moças jovens são realmente fáceis de se quebrarem. De um certo ponto de vista, as mulheres jovens se quebram quando amam. Assim pensava eu.

- Então, agora, dentro do meu sonho, não estaria ela catando os seus próprios cacos?

\section{O RELÕGIO (Tokei)}

O pobre doutor em leis, quando trabalhava no escritório de advocacia na defesa de um incidente de corrupção envolvendo um vereador, ganhou inesperadarnente uma certa quantia em dinheiro, juntamente com uma amiga bonita.

Ele a convidou para ir ao teatro.

Da porta do teatro, subiram num pequeno táxi. Era a primeira vez que andava de carro desde que nascera. Era uma pessoa que evitava até um ônibus: mesmo quando fôra a uma estância de águas meio ano antes, sacudira-se numa carruagem.

O ar se recortava dentro da caixa estreita e, enquanto sustinha os sentidos da jovem mulher, concentrando-os, seu coração se encolhia tão covardemente que acabou esquecendo seu próprio lugar dentro do carro que corria através da noite fria sem sons de vento. De repente, disse distraidamente:

- Só havia táxi de segunda classe naquele teatro. Mas andar até um ponto onde houvesse bons carros exigiria muita paciência, pois está frio.

- Sim, disse ela levemente, virando a face como se fosse perguntar algo. Mas ele acrescentou muito mais rapidamente:

- Mas, além de fazer barulho, a caixa é pequena e, ao contrário do que se esperava, continua frio.

E, como se fosse se certificar de algo, bateu no banco duro, desnudado de tapetes:

- Veja isto. É deprimente. 
- E.

A mulher não conseguiu encontrar uma resposta adequada. Acabou se desapontando por sentir em si uma leve auto-aversão.

Ele estendeu a mão, subitamente, de modo brusco, como se fosse virar o braço dela que estava sobre o joelho, com a intenção de mudar o rumo da situação.

- Agora, que horas?

A moça respondeu agudamente, sem pensar:

- Ah, este relógio é uma droga!

Ele retirou a mão, surpreso. A mulher corou.

- Este relógio é realmente ruim. A forma não segue o fino desenho do braço, é japonês. Made in Japan, viu? Fora de moda. Quando você reparou que eu tenho um relógio? Já olhou até o fundo da manga?

Ele emudeceu e nem sequer esboçou um elogio.

- Mas é uma recordação de mamãe. Por isso ainda o tenho. Uso-o constantemente por ser lembrança de minha mãe; é um pouco velho, não?

- Então, ainda está ouvindo os sons de sua mãe?

- Os sons de minha mãe? É, é isto. Made in Japan, como mulher à moda japonesa.

- Como?

Ele tomou a mão da moça um tanto despreocupadamente, pela primeira vez, e a levou ao seu ouvido. rapazes!"

— E, está ouvindo? Mamãe está dizendo: "Não vá sair com

Ela sorriu. O tremor da face que tocava seu braço se transmitiu a seu corpo.

Não se podia, irrefletidamente, desdenhar a vaidade de ambos. A conseqüência casual da vaidade frente às mulheres do mundo proporcionou a ele, que sentia medo, um pouco de força em relaçăo ao amor.

Deste fato se conclui que, resumindo-se, o amor talvez seja uma coisa sem sentido que se realiza utilizando-se de qualquer coisa.

Mas este incidente, além disso, indicou uma mudança em sua vida, talvez mesmo um avanço no sentimento da vida. Só pelo motivo dele ter apenas tocado levemente sua pele, ele poderia até pensar desta forma: 
- Pegando este relógio-de-pulso dourado e indo a uma casa de penhores, vou transformar esta formosa mulher e fazê-la embalar a criança por ela gerada.

\section{PôR-DO-SOL (Rakujitsu)}

A mulher míope, afobada e apressada, no jardim do correio de segunda categoria, escrevia um cartão postal vedado.

- A janela do trem - A janela do trem - A janela do trem Escrevia três vezes e três vezes apagava. - Os dias de hoje - Os dias de hoje - Os dias de hoje.

O funcionário encarregado da entrega expressa coçava a cabeça com o lápis.

$\mathrm{Na}$ cozinha de um grande restaurante, o chefe de cozinha dava o laço no avental novo da garçonete. seio pela frente.

- $O$ quê?

Até o poeta compra açúcar. O garoto da loja de açủcar trespassava a colher na montanha de açúcar.

- É. Pélo contrário, desistamos de assar o mochi. Se colocássemos o açúcar num bolso e andássemos pela cidade, talvez surgisse uma branca visão.

Então, o poeta murmura para a multidão dos que iam em sentido contrário:

- Quantas pessoas que caminham em direção ao passado! Eu estou caminhando para o futuro. $\mathrm{E}$ então, as pessoas que vão na mesma direção que eu?... Também para o futuro? absurdo!

A bicicleta do jovem do correio rodeou a mulher míope.

- Sim! Sim!

- Ei, eu sou míope. Nem sequer vejo o branquíssimo açúcar do vendedor. Pensei que ele estivesse na janela do trem com ela! Aquela pessoa ainda hoje me...! - Ei, carteiro!

A garçonete estava sorrindo no restaurante, junto com o poeta.

- É um avental novo, não é? Mostre-me atrás. Bem no meio das costas, há uma borboleta branca recém-pousada.

- Não, não veja o meu passado. mos.

- Tudo bem. Andei em direção ao futuro e nós nos encontra- 
Nesta hora, o sol, cuja trajetória vinha do leste e terminava a oeste e que até agora se enganchava no telhado do depósito ảa loja de penhores, se pôs abruptamente sem emitir som algum.

- Oh! - As pessoas que andavam por esta estrada, todas, neste instante, emitiram um pequeno suspiro, titubearam apenas três passos. Mas, não se conscientizaram disto.

As crianças que estavam brincando no fim do leste da estrada viraram a oeste, encolheram os pés todos juntos e, posicionando-se, pularam. Tentavam capturar com os olhos o sol, que se tinha posto.

- Posso ver!

- Posso ver!

- Posso ver!

Diziam apenas mentiras. Pois se não podiam ver nada ... !

\section{TROVÃO DE OUTONO (Akino Kaminari)}

Era começo de outono, as moças que voltavam da praia percorriam a cidade como excelentes cavalos baios; numa sala do hotel, ouvia-se a flauta antiga, enquanto nossas núpcias... o relâmpago agitou bruscamente a janela de vidro: foi um reverberar de trovão que parecia atingir e destruir este casamento. A noiva de dezessete anos empalideceu, fechou as pálpebras e, qual bandeira molhada, caiu desmaiada.

\section{- A janela! Fechem a janela!}

Depois, terminada a cerimônia, o pai da noiva:

- O pavor de minha filha ao trovão talvez seja maldição de alguém - narrou a biografia do devotado filho de Tamba.

- No país de Tamba, na comarca de Amada da vila Haji, Shichizaemon Ashida era um filho tão devotado que foi honrado pelo senhor feudal, que aboliu a taxa por suas terras; mas sua mãe odiava o trovão a ponto de perder a consciência quando ouvia até mesmo o som de um tambor, de maneira que quando o trovão ameaçava soar, mesmo que estivesse em qualquer lugar, Shichizaemon voltava voando para casa. No verão, nem sequer ia à vila vizinha. $E$ isto não é tudo. Mesmo depois da morte da mãe, quando ouvia o trovão, corria ao cemitério e protegia a lápide da mãe abraçando-a.

Então, numa certa noite de tempestade, Shichizaemon, compadecido, cobrindo a lápide da mãe, foi atingido pelo trovão e acabou morrendo. A manhã seguinte clareou bonita e quando os habitantes da vila tentaram soltar o braço de Shichizaemon, que estava preso à tumba, este se soltou. O cadáver carbonizado era um homem de cinzas que se desmanchava em pedaços a um simples toque. Enten- 
deram que seria um erro tentar separar o devotado filho da tumba da mãe. Uma velha catou um dedo que estava caído por ali e venerava-o, enquanto o guardava na manga do quimono.

- Vou fazer meu filho desobediente beber um chá deste dedo.

Cada um dos habitantes da vila catou pedaços do cadáver.

- Essas cinzas foram transmitidas de geração para geração de antepassados como se fossem um tesouro; também em minha casa, quando pequeno, minha mãe me fez tomar. Será que é por isso que também eu e minha filha não gostamos de trovão? noiva.

- Você fez sua filha também... - disse eu, imitando o pai da

- Você fez sua filha também tomar estas cinzas?

- Não, na verdade esqueci-me totalmente... Mas, se o sogro quiser que a faça beber, vou buscar logo o pequeno pacote.

A casa nova do subúrbio - quando chegamos à casa nova, subitamente vieram pulando, daqui e dali, quatro grilos, de trás da capa que cobria o gaveteiro da noiva. Mas a noiva, claridade de início de verão, qual ramalhcte de flores lilases - e sons enfurecidos de trovão, como se fossem de novo fazer o verão se suicidar - eu abracei a assustada noiva infantil, mas a primeira coisa que senti de sua pele foi a mãe que há dentro da mulher. Então, se abraçar esta lápide macia e quente, será que não me transformarei num cadáver carbonizado?

O relâmpago se agitou, o trovão estava sobre o telhado como se fosse transformar esta cama de recém-casados em cama mortuária.

- A cortina! Fechem a cortina!

\section{CANÁRIOS (Kanariya)}

\section{Senhora,}

Fui obrigado a lhe enviar esta carta, quebrando ainda uma vez nosso acordo.

Os canários que me deu no outro ano não poderão ser mais tratados por mim. Minha esposa é quem cuidava deles. Meu papel era apenas contemplá-los. Contemplando-os, lembrava-me da senhora...

Devo dizer que era uma boa lembrança... "Você tem uma esposa, eu tenho um marido, vamos nos separar. Ao menos se você não tivesse uma esposa... Ofereço estes canários para você se lembrar de mim. Por favor. Estes canários formam um casal. Mas os canários, um macho e uma fêmea, foram juntados pelo acaso. Talvez seja esquisito dar coisas vivas como lembrança. Mas nossas recor- 
dações também são vivas. Se chegar um tempo em que as recordações de nossa reciprocidade devam morrer, deixemo-las morrer."

Estes canários estão prestes a morrer. Já não há quem cuide deles. Não consigo alimentar os trágeis pássaros pois sou pintor pobre e negligente. Vou ser claro. Minha esposa, que cuidava dos passarinhos, morreu. Morrendo, também os canários devem morrer... Pois então, senhora! Será que era minha esposa quem fazia com que eu mantivesse vivas suas recordações?

Pensei em soltá-los no céu. Mas desde que minha esposa morreu, parece que as asas enfraqueceram de repente. Além do mais, eles não conhecem o céu. Este casal não tem nenhum pássaro amigo entre a multidão, nem na floresta vizinha, nem nesta grande cidade. Se os dois se separassem e continuassem voando, teriam mortes solitárias. A senhora dizia que algum avicultor juntara, ao acaso, um macho e uma fêmea numa gaiola?

É um desgosto vendê-los ao avicultor. Porque é um presente da senhora. Também é um desgosto devolvê-los. Porque eram pássaros dos quais minha esposa cuidava. Além do mais, talvez a senhora tenha se esquecido deles.

Repetindo. Porque minha esposa existia, os canários estavam vivos até hoje. Como lembranças da senhora... Por causa disso, quero fazê-los morrer junto com minha esposa. Não são apenas recordações. Por que será que eu consegui amar alguém como a senhora? Não será porque minha esposa existia? Ela me fazia esquecer completamente os sofrimentos da vida material. Ela me fazia não perceber esta metade da vida. Se não fosse assim, frente a uma mulher como a senhora, não baixaria eu os olhos ou os afastaria firmemente?

Senhora. Seria melhor matar estes canários e enterrá-los no túmulo de minha esposa. Não concorda?

\section{INTERMEDIAÇÃo DO PARDAL (Suzumeno Baishaku)}

Habituado a morar numa solidão egoísta, ele tornou-se, afinal, admirador da beleza do ato de presentear seu próprio corpo a um estranho. Compreendeu o valor do sacrifício. Era uma semente de um grão com a finalidade de transmitir a chamada raça humana do passado para o futuro, e se satisfez com o fato de se sentir minúsculo. A dita raça humana se formou junto a vários tipos de minerais e vegetais e concordou com o pensamento de que não se trata de uma existência particularmente mais valiosa do que a de outros animais e vegetais, pois não passa de uma pequena coluna que sustenta uma vida. imensa que flutua neste universo.

— Está bom? 
A prima mais velha rolou uma moeda sobre a penteadeira. Enquanto a pressionava fortemente na palma-da-mão, olhou-o com o semblante grave. Ele colocou seu coração melancólico nesta mão branca.

- E coroa.

- Coroa? Antes terá que decidir. Se sair coroa, você vai se casar com ela? Ou não?

- Casarei.

- Ei! Deu cara!

- Ah, é?

- Hum, mas que resposta mais insipida!

A prima riu alto Levantou-se, jogando a fotografia da moça. Ela era uma moça que ria muito. Esta risada ressoa alegremente por longo tempo. $\mathrm{E}$ faz todos os homens que se encontram na casa sentirem, pela audição, estranhos ciúmes.

Apanhou a foto e olhou para a moça. Até que seria bom se se casasse com ela, pensou. Pensou que ainda devia existir, no Japão, muitas mulheres que se casavam, entregando seu próprio destino nas mãos de pais e irmãos, pois eram gentis a. este ponto para com o próximo. Achou bonito este costume. Achou feio seu ser que hesitava, mesmo consciente de seu egoísmo estúpido.

- Pensando bem, escolher o cônjuge é algo que se julga no cara-ou-coroa, como se se tirasse a sorte. - Quando a prima disse isto, também ele sentiu uma grande alegria no fato de depositar completamente seu próprio destino na moeda sob sua palma branca. Mas, compreendendo que não passava de uma gozação por parte dela, seu olhar acabou por pousar, tristemente, na fonte defronte à varanda.

Se houvesse outra mulher além desta que pudesse ser sua esposa, pediu à fonte que refletisse na água o seu rosto. Acreditava que o homem podia ver através, tanto do tempo, quanto do espaço. Era solitário a este ponto.

Uma pedra pontiaguda de Deus afundou obscuramente em direção ao campo de visão dele, que contemplava a superfície da água, com toda a alma. Dois pardais caíram do telhado quando copulavam. Os pardais, em vôo rasante sobre a superfície da água, separaram-se e alçaram vôo em direções diversas. Ele compreendeu esta iluminação divina.

- Então, é isso? - murmou.

As pequenas ondas da superfície da água se desmancharam silenciosamente. Seu coração se tornou um espelho tal qual a superfície da água. A imagem de um pardal se refletia claramente. Este par. dal cantou. Foi este o significado de seu canto: 
- Você que está hesitante, não vai acreditar se eu lhe mostrar a imagem da mulher que se tornará sua esposa nesta encarnação. Então, vou lhe mostrar a imagem da esposa em sua próxima encarnação.

Ele disse ao pardal:

- Pardal, eu lhe agradeço. Se eu nascer pardal na próxima encarnação, e a tiver por esposa, vou decidir desposar esta moça: Quem vê o destino da próxima encarnação, não hesita nesta. A esposa valiosa e bela da próxima encarnação intermedia o casamento desta encarnação.

Então, fazendo uma singela saudação à moça da foto, sentiu crescer a presença de Deus.

\section{ALGUMAS CONSIDERAÇÕES}

A trajetória de Kawabata segue, depois destes escritos, o caminho que o levaria ao Neo-sensacionalismo: exploração dos elementos sensoriais como motor próprio da narrativa, desvirtuando portanto a seqüência cronológica em todos os seus níveis, extremo cromatismo na descrição, recursos surrealistas, montagem, colagem de elementos dispares, diacronia tempo-espaço, entre outros, provenientes de nítida inspiração ocidental das vanguardas do início do século. Mas é curioso notar que, nestes pequenos textos, já encontramos muitas destas caracteristicas: em Recipientes Frágeis, um certo clima surreal comenta e renova um dito bíblico através da analogia onírica: em Pôr-do-sol, uma composição em colagem fragmenta a percepção do tempo através de vários personagens; em Trovão de Outono a mística macabra de antigas estórias ganha novas proporções na interpenetração com os tempos modernos e o amor filial e marital. Mesmo num texto tão singelo como Canários, encontramos, através da reiteração, um clima um tanto quanto hipnótico.

Mas ao mesmo tempo, o mundo de Kawabata é um mundo onde personagens e situações são de uma sutileza tão requintada quanto cotidiana: pequenos incidentes diários são transmutados em profundas reflexões sobre a essência dos sentimentos que provocam e permeiam todas as ações. O escritor explora e aprofunda a psicologia do ser humano, desnuda-o, mas não ao modo cientificista: seus personagens apenas deixam entrever, qual ponta de iceberg, toda a imensa profundidade de suas emoções, que permanecem no reino do não-dito.

Uma caracteristica fundamental, que ao Ocidente parece ser tradicionalmente japonesa, é a da concisão, tanto do ponto de vista plástico (lembremo-nos da economia da linha nos desenhos), quanto do literário (a tradição do haik u nos mostra bem como dizer muito com muito pouco). Outra característica fundamental, esta lingüística, é a de que no japonês os liames sintáticos são mais tênues, menos dependentes e menos fechados do que nas línguas ocidentais: pode- 
mos construir um periodo imenso sem necessidade de pontuação. Ora, podemos, pois, relacionar todos estes contos como se fossem renga (poesia derivada do hailcu mas que não tem fim, podendo sempre serem acrescentados mais versos), onde o nexo entre eles cria sempre uma nova face da mesma matéria: a vida e os sentimentos entre os personagens, suas hesitações, seus valores, suas fraquezas e virtudes.

O mundo de Kawabata é o mundo do subjetivo.

(1) Os textos traduzidos por Madalena Natsuko Hashimoto, sob a orientaçåo de Geny Wakisaka, foram obras estudadas no Curso de Literatura Japonesa II, da F.F.L.C.F. da USP, no ano de 1985. 